\title{
Evaluation on the Competitiveness of Chinese Online Peer-to-Peer Lending Platform Based on Back Propagation Artificial Neural Network
}

\author{
Cao Yimei ${ }^{1}$, Long Jiancheng ${ }^{2}$ \\ ${ }^{1,2}$ School of Economics and Management, XIDIAN University, 266 Xinglong Section of Xifeng Road, Xi' an, Shaanxi 710126
}

\begin{abstract}
This article tries to build the competitiveness evaluation index system of Chinese online peer-to-peer lending platforms covering 6 first class indicators and 16 second class indicators from the perspectives of apparent competitiveness and connotative competitiveness, after which a competitiveness evaluation model of 16-10-1 structure is established based on back propagation artificial neural network, followed by empirical studies on the competitiveness of Chinese online peer-to-peer lending platforms to verify the effectiveness of the Model.
\end{abstract}

Keywords: online peer-to-peer lending platform, competitiveness, back propagation artificial neural network.

\section{Introduction}

The year 2015 witnessed the adjustment and standardization of Chinese online peer-to-peer lending industry. As the competition becomes increasingly fierce, comprehensive strength of an online peer-to-peer lending platform has been highlighted as the booster for its continuous development. Therefore it is of great significance for platforms to clearly recognize respective competitive edge in the midst of the rat race and make strategic decisions accordingly. The ultimate goal of the assessment on platforms' comprehensive competitiveness lies in estimating their rankings in the whole industry and further contributing to the favorable resolutions.

Existing studies and evaluations on enterprises' competitiveness, in most cases, adopt analytic hierarchy process (AHP), data envelopment analysis (DEA) and factor analysis. However, AHP is always regarded subjective since it is difficult to decide the weight assigned to each tier. DEA has particularities in terms of every decision-making unit (DMU) as it calculates weight from the most favorable perspective although DEA's evaluation results often boast strong objectivity for it is based on relative concepts. Thus, the results obtained by DEA are not comparable and may not correspond to objective reality. Factor analysis method is a multivariate statistical method to reduce data through dimensionality reduction whose advantage is to process masses of data and assign weight in accordance with the contribution, thus avoiding deciding weight subjectively as that in AHP, whereas the disadvantage is the overall score of the factors is directly related to sample size, which means the change of sample numbers may change the ordering, and easily exerts subjective influence on the meaning and explanation of each factor.

Artificial neural network technology enjoys distinct superiority in solving multi-index comprehensive evaluation problem and is adept at making decisions in similar, indeterminate and even contradictory knowledge environment. It can avoid factitious weight design and correlation coefficients calculation, thus suitable to address the problem of incomplete information, vast analysis indexes and non-linear correlation among some indicators in the midst of carrying out enterprise' competitiveness evaluations. Among all the neural network models, the most representative and widely used is back propagation artificial neural network which has clear thinking, well-knit structures, stable working conditions and strong operability. With that, this article tries to build an effective back propagation artificial neural network model to evaluate the competitiveness of online peer-to-peer lending platforms in an objective manner and get the rankings of different enterprises in the industry.

\section{The Fundamentals of BP Artificial Neural Network}

BP artificial neural network, as one of the most widely applied neural network, is a multi-layer feed-forward one based on error back propagation algorithm consisting of information forward propagating and error back propagating (see Figure 1). The three layer network, namely input layer, hidden layer and output layer, achieves complete connection among different layers and no connection among separate neurons.

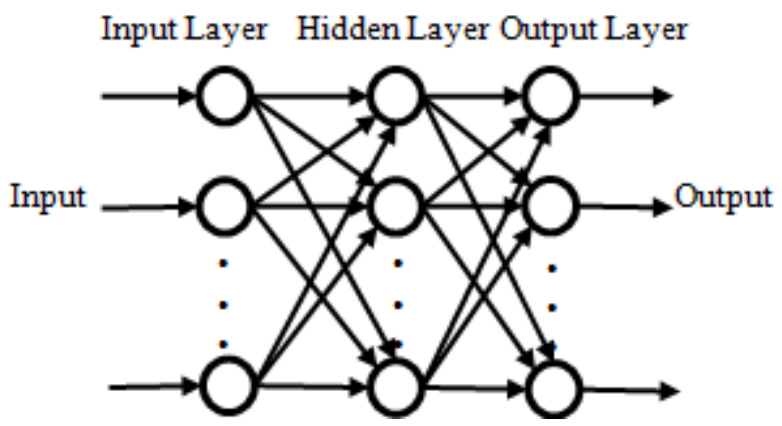

Figure 1: BP artificial neural network topology

When the learning sample is imported, neurons in input layer is responsible for receiving information from the outside and passes it to neurons in hidden layer where the information is processed and its transformation is conducted. Hidden layer can be designed as either single hidden layer or multi-hidden layer structure in line with the specific needs of information changing capacities. Information transferred to the output 


\section{International Journal of Science and Research (IJSR) \\ ISSN (Online): 2319-7064}

Index Copernicus Value (2015): 78.96 | Impact Factor (2015): 6.391

layer through the last hidden layer can export outcomes through further processing, thus finishing the forward propagating of learning.

When the actual output is in discrepancy of the desired output, error back propagating begins. Error shall go through output layer, amend each weight, and counter-propagate to hidden layer and input layer. The forward propagation and error back propagation of information is the process of each layer to adjust each weight as well as the process for neural network to learn and get trained which cannot stop until the error is reduced to the acceptable range or the preset leaning times are finished.

In addition, during the learning process of neural network, the desired output of a sample are supposed to be known quantity obtained through historic statistics, specialist marking or mathematical statistical analysis. This article adopts multiple-factors associative effects index (MFAEI) from www.wdzj.com, an authoritative third party information platform on online peer-to-peer lending, as the desired output of online peer-to-peer lending platform.

\section{The Establishment of Competitiveness Evaluation Index System}

The competitiveness of an enterprise refers to its comprehensive ability to more continuously and effectively provide products or services for markets, namely consumers including productive ones, to gain profits and selfdevelopment. It is believed that the competitiveness of an enterprise is a complex system and a joint result of multitudinous potential influence factors [1].

\subsection{Construction idea behind evaluation index system of enterprises competitiveness}

Existing theories on enterprises' competitiveness analyze determinants during the competition from different perspectives. According to school of the exterior market structure of Michael Porter, enterprise competitive edge mainly lies in two aspects: long-term profitability and the position of the enterprise, which lays great emphasis on the assessment of competitiveness from the perspective of environment and the influence of external environment factors exerting on the enterprise, whereas the internal factors are almost ignored. On the contrary, resource-oriented school holds the view that tangible resources, intangible resources and accumulated knowledge of an enterprise altogether play a pivotal role in gaining sustainable competitive advantages. Forming and utilizing such exclusive resources is the secret for maintaining competitive edge. While ability-oriented school regards core competence, the inherent ability that cannot be imitated and copied, is the root for sustainable competitive advantages, deeming that solely depending on one or some abilities can bring nothing but temporary competitive edge for an enterprise.

The above points of view demonstrate that existing theories simply put forward the determinants of enterprise competitiveness from a certain perspective, yet enterprise competitiveness is a complicated and broad concept which can be influenced by numerous factors. In this article, the influencing factors of enterprise competitiveness is divided into two categories from the perspective of space, namely the internal factors and external factors, and the former can be further sub-divided into ability factors and resource factors including management and innovation ability of an enterprise and its technologies, brands, human resources and so on while the latter refers to the industrial environment and social and economic environment where the enterprise lies. In addition, the establishment of competitiveness evaluation index system in this article follows the principles listed below: (1) Scientificity: the index system must reflect the essential characters of the competitiveness of online peer-to-peer lending platforms. (2) Systematization: the index system are supposed to have reasonable layers and structures and certain logical relations among indexes of different layers must exist to comprehensively reflect the condition of evaluation object. (3) Comparability: the designed index system must be capable of conducting horizontal and vertical comparison. (4) Feasibility: the data needed in the index system must be reached and all the indexes can be effectively counted and measured.

With that, the establishment of competitiveness evaluation index system in this article will first analyze the outward manifestation characters and inherent potential factors of enterprise competitiveness and then change the relevant factors to operable evaluation indexes in line with the principles of scientificity, feasibility and so on.

\subsection{Competitiveness evaluation index system of Chinese online peer-to-peer lending platforms}

The essence of online peer-to-peer lending platform is the enterprises trading information, so the establishment of competitiveness evaluation index system should be first analyzed from distinct characters and potential factors. Revealed competitiveness can be manifested by market performance and reflect an enterprise's overall strength based on the integration of external environment and internal resources, thus it can most directly reflect enterprise competitiveness. Distinct competitiveness is mainly demonstrated by enterprise's financial condition and market performance. Potential competitiveness means the resources and abilities an enterprise boasts in certain environment and serves as internal boosters for achieving sustainable development and maintaining competitiveness. Considering that enterprise competitiveness is the joint result of external distinct market performance and internal potential competitiveness, this article build the evaluation system from the dual perspective of distinct factors and potential factors covering 6 first class indexes and 16 second class indexes (see Table 1).

Technical index, brand index and compliance index is obtained by comprehensively examining and weighing relevant indexes. 


\section{International Journal of Science and Research (IJSR) \\ ISSN (Online): 2319-7064}

Index Copernicus Value (2015): 78.96 | Impact Factor (2015): 6.391

Table1: The competitiveness evaluation index system of Chinese online peer-to-peer lending platforms

\begin{tabular}{|c|c|c|}
\hline $\begin{array}{c}\text { Competitiveness } \\
\text { levels }\end{array}$ & $\begin{array}{l}\text { First class } \\
\text { indexes }\end{array}$ & Second class indexes \\
\hline \multirow{4}{*}{$\begin{array}{l}\text { Distinct } \\
\text { competition }\end{array}$} & \multirow{2}{*}{ Scale } & Volume \\
\hline & & Loan balance \\
\hline & Benefit & Registered/capital \\
\hline & Growth & Volume growth rate \\
\hline \multirow{12}{*}{$\begin{array}{l}\text { Potential } \\
\text { competition }\end{array}$} & \multirow{4}{*}{ Resource } & The number of investors \\
\hline & & The number of borrowers \\
\hline & & Technical index \\
\hline & & Brand index \\
\hline & \multirow{6}{*}{ Ability } & Operating index \\
\hline & & Run time \\
\hline & & $\begin{array}{l}\text { Time-consuming of successful } \\
\text { borrowing }\end{array}$ \\
\hline & & $\begin{array}{l}\text { The proportion of the top ten } \\
\text { amount to be repaid }\end{array}$ \\
\hline & & $\begin{array}{l}\text { The proportion of the top ten } \\
\text { amount to be received }\end{array}$ \\
\hline & & Leverage fund \\
\hline & \multirow[t]{2}{*}{ Environment } & $\begin{array}{l}\text { Per capita GDP of platforms } \\
\text { registered }\end{array}$ \\
\hline & & Compliance index \\
\hline
\end{tabular}

Technical index represents technical strength of the platform which is gained in accordance with independent $R \& D$ capacity, average response time, web security vulnerability detection, APP update frequency, WeChat client, data transmission security, account security and IT ability.

Brand index measures the popularity of the platform which can be calculated based on the degree of capital recognition, online time, headquarter city, Alexa ranking, shareholder background, team background, media coverage, venture capital, and event impact.

Compliance index shows the current degree of a platform's compliance and its difficulty of compliance transformation which quantifies each business requirement and prohibition according to regulators and grades the compliance of the platform in gradient manner. It consists of over 20 indicators including whether the operation capitals have been put into the bank, whether the loan balance exceed the ceiling. The higher index means the better compliance degree or the easier for the platform to transform.

\section{Competitiveness evaluation index system of Chinese online peer-to-peer lending platforms based on BP artificial neural network}

\subsection{Sources and standardization of data}

Data for this article come from www.wdzj.com and wind database.

Before establishing BP artificial neural network model, all the indicators' data need to be standardized to eliminate the different dimensions. The standardization of the data is conducted based on the following principles:

(1) The evaluation target is better when the indicator is larger, the data standardization is calculated by the following formula:

$$
F_{\mathrm{i}}=\left(X_{\mathrm{i}}-X_{\min }\right) /\left(X_{\max }-X_{\min }\right)
$$

(2) The evaluation target is better when the indicator is smaller, the data standardization is calculated by the following formula:

$$
F_{\mathrm{i}}=1-\left(X_{\mathrm{i}}-X_{\min }\right) /\left(X_{\max }-X_{\min }\right) \text {. }
$$

Where, $F_{\mathrm{i}}$ is the normalized value of the ith indicator, $X_{\mathrm{i}}$ is the value of the ith indicator, and $X_{\max }$ and $X_{\min }$ are the maximum and minimum values of the ith indicator respectively.

\subsection{Modeling procedure}

(1) Design neural network structure. Existing studies show that any continuous function in a closed interval can be approached by a connotative BP artificial neural network; therefore, a three-layer BP artificial neural network can finish the map from any $\mathrm{n}$ to $\mathrm{m}$ dimension. This article designs a three-layer BP artificial neural network with a hidden layer, among which the number of neurons of input layer is the number of indicators; the number of neurons of output layer is the competitiveness index of online peer-to-peer lending platforms, so the number of neurons of output layer is 1 ; the number of neurons of hidden layer is given by the formula $\sqrt{(n+m)}+a$, where $\mathrm{n}$ is the number of input layers, $\mathrm{m}$ is the number of output layers and a is any number between land 10, which is determined by training several times.

(2) Train neural network. Use the 16 competitiveness evaluation indicators value of each platform as input data of neural network and the MFAEI as target data and train the neural network by Matlab.

(3) Examine neural network generalization ability. Compare errors between actual output and desired output. When errors are less than set values, the weight value and threshold value held by neural network is the right internal representation of the network through adaptive learning.

4.3 The achievement of competitiveness evaluation index system of Chinese online peer-to-peer lending platforms based on BP artificial neural network

\subsubsection{Create a neural network structure}

Matlab provides the toolbox to effectively and quickly establish BP artificial neural network by some simple operation interface, and the callout command is nntool. The establishment of BP artificial neural network requires determining training function, the weight value and threshold value of neural network, adaption learning function, the number of neurons of hidden layer and the activation function of each layer. This article chooses TRAINSCG, namely conjugate gradient method, as the training function based on the results of many tests since the training will automatically stop when there is no convergence and the time required is less than other algorithms. As for adaption learning function, this article adopts LEARNGDM, a weight-learning algorithm is presented using the gradient descent method with batch process and adding a momentum item. LOGSIG as activation function will make hidden layer output always remains [0,

1]. Based on the above settings, this article builds the structure

Volume 6 Issue 1, January 2017 


\section{International Journal of Science and Research (IJSR) \\ ISSN (Online): 2319-7064}

Index Copernicus Value (2015): 78.96 | Impact Factor (2015): 6.391

of BP artificial neural network as shown in Figure 2. The number of neurons of input layer, namely evaluation indexes, is 16 while there is only one neuron on output layer whose computation can be regarded as the score of samples. According to, the number of neurons of hidden layers is [5, 15]. Within this scope, this article tries different number of neurons of hidden layer to repeatedly train the neural network and finally determines the Number as the one which can minimize the sum of absolute values of error by comparing each result, that is 10 . Therefore, this article builds the 16-10-1 BP artificial neural network to evaluate the competitiveness of Chinese online peer-to-peer lending platforms.

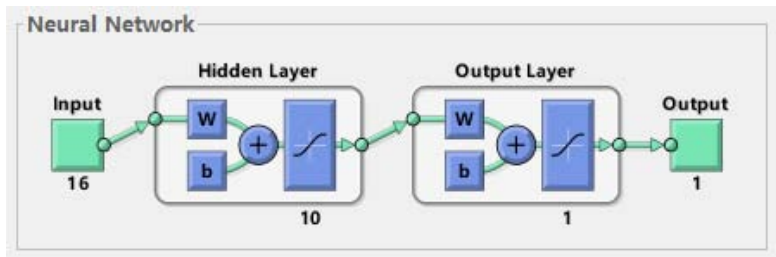

Figure 2: Neural network model fitting graph

\subsubsection{Train the neural network}

There are 30 samples included in the sample set, and this article randomly select 25 of them as training samples and the remaining 5 as test samples. Training samples by TRAINSCG asks for the following parameters:

Epochs: the maximum cycle index is set as 1000 ;

Goal: required accuracy is $1 \mathrm{e}-05$;

max fail: the maximum number of validation data failure times is 1000 .

\subsubsection{Evaluation results of competitiveness}

Randomly select 25 training samples and train them in the BP artificial neural network model. When the iteration of the network is at epoch109, the MSE of network error reaches the validation of goal $=1 \mathrm{e}-05$. The convergence result is satisfying (see Figure 3).

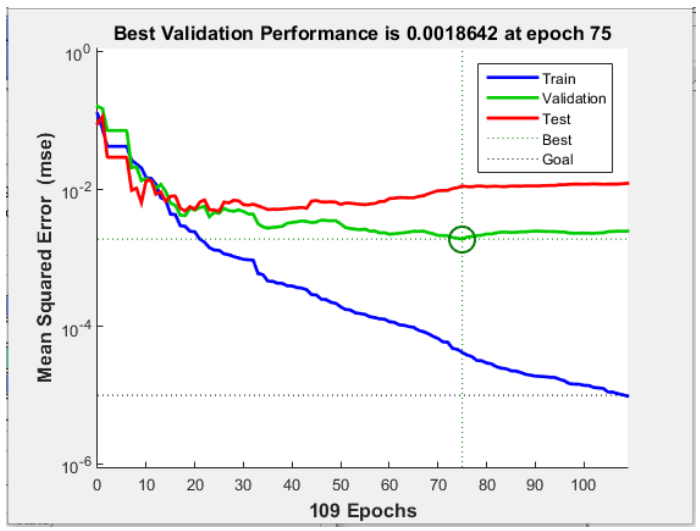

Figure 3: Neural network model training error chart

To test the effectiveness of the established network model, input the remaining 5 samples to the well-trained network to predict the competitiveness of 5 enterprises (see Table 2). The errors between simulation output data and target data is quite small and tolerable, which shows that the evaluation model built in this article can precisely assess the competitiveness of Chinese online peer-to-peer lending platforms.
Table2: The Simulation results comparison table

\begin{tabular}{|c|c|c|c|}
\hline Sample & Output data & Target data & Error data \\
\hline S1 & 0.85264 & 0.85406 & 0.0014205 \\
\hline S2 & 0.6558 & 0.71555 & 0.059747 \\
\hline S3 & 0.55517 & 0.58339 & 0.028224 \\
\hline S4 & 0.31127 & 0.35654 & 0.045262 \\
\hline S5 & 0.30634 & 0.32438 & 0.018038 \\
\hline
\end{tabular}

\section{Conclusion}

This article builds the competitiveness evaluation index system of Chinese online peer-to-peer lending platforms covering 6 first class indicators and 16 second class indicators from the perspectives of dominant characters and potential factors. The competitiveness evaluation of online peer-to-peer lending platforms based on artificial neural network reaches learning requirement of target error after 109 iterations and establishes BP artificial neural network model of 16-10-1 structure. The slight error (absolute error between 0.0014 and 0.06 ) between simulation results and desired values of test sample demonstrates the effectiveness of this model. Therefore, the BP network model in this article can significantly reduce the influence of subjective factors and random factors, precisely evaluates the competitiveness of Chinese online peer-to-peer lending platforms, and serves as a way of measuring for each platform to comprehensively assess respective position in the industry, thus making strategic decisions in accordance with self-development.

\section{References}

[1] Jin Bei. A Study on the Nature of Enterprise Competitiveness [J]. China Industrial Economy, 2001, (10): 5-10.

[2] Yamoah, Fred Amofa. Sources of Competitive Advantage: Differential and Catalytic Dimensions [J]. Journal of American of Business, 2004, 4(3): 223-227.

[3] Prahalad C. K., G. Hamel. the Core Competence of the Corporation [J]. Harvard Business Review, 1990, (5): 79-91.

[4] Wernerfelt Birger. A Resource-based View of the Firm [J]. Strategic Management Journal, 1984, 5(2): 171-180.

[5] Guo Haifeng, Chen Xiao. A Study of the Comprehensive Competitiveness Evaluation of P2P Network Lending Platform [J]. Finance Forum, 2015, (2): 12-23.

[6] Daniel Santin, Francisco J. Delgado, Aurelia Valino. the Measurement of Technical Efficiency: A Neural Network approach [J]. Applied Economics, 2004, 36(6): 27-35.

[7] Fish K. E, Johnson JD, Dorsey R. E, Blodgett JG. Using an Artificial Neural Network Trained with a Genetic Algorithm to Model Brand Share [J]. Journal of Business Research, 2004, 57(1): 79-85.

[8] Zhang J, Morris J. Process Modeling and Fault Diagnosis Using Fuzzy Neural Networks [J]. Fuzzy Sets and Systems, 1996, (79): 127-140.

[9] Guo Lan, Zhang Xiangjian. Assessment of Enterprise Core Competence Based on BP ANN [J]. Studies in Science of Science, 2007, 25(1): 132-137.

[10] Wen Xin, MATLAB Neural Network Simulation and Application [M]. Beijing: Science Press, 2003.

\section{Volume 6 Issue 1, January 2017 www.ijsr.net}




\section{International Journal of Science and Research (IJSR) \\ ISSN (Online): 2319-7064}

Index Copernicus Value (2015): 78.96 | Impact Factor (2015): 6.391

\section{Author Profile}

Cao Yimei is now pursuing Master degree since 2014 under the guidance of Prof. Long Jiancheng. Her specialization area is Finance.

Long Jiancheng is working as a professor in XIDIAN UNIVERSITY. His specialization lies in modern enterprises system and financial theory. 